\section{Central Bank Structure, Policy Efficiency, and Macroeconomic Performance: Exploring Empirical Relationships}

Stephen G. Cecchetti and Stefan Krause

\section{INTRODUCTION}

$\triangle 1$ 11 economists agree that more information is better than less. When people are better informed, they make better decisions, enhancing the efficiency of the economy in allocating resources and improving overall welfare. It would be difficult to find an area of economic life where this line of argument has carried more weight than it has in central banking circles in recent years.

The job of central bankers is to conduct monetary policy in order to promote price stability, sustainable growth, and a stable financial system. They do this in an environment fraught with unavoidable uncertainties. But in conducting policy, there is one uncertainty that policymakers can reduce: the uncertainty they themselves create. Everyone agrees that monetary policymakers should do their best to minimize the noise their actions add to the environment. The essence of good, transparent policy is that the economy and the markets respond to the data, not to the policymakers.

The result of this agreement is that today we have the nearly universal and immediate public broadcast of all interest rate changes. As everyone in financial markets around the world knows, the Federal Reserve's Federal Open Market Committee (FOMC) makes a public statement at 2:15 p.m. EST following each meeting. But the first public announcement of a move in the federal funds rate target was made on February 4, 1994, and the regular issuance of a statement became an official feature

\footnotetext{
Stephen G. Cecchetti is a professor of economics at The Ohio State University and the National Bureau of Economic Research. Stefan Krause is an assistant professor of economics at Emory University. The authors thank Alfonso Flores-Lagunes, Dino Kos, Roisin O'Sullivan, and Daniel Thornton for comments and discussions, as well as Gabriel Sterne for assistance with the data.

(1) 2002, The Federal Reserve Bank of St. Louis.
}

of the FOMC's procedures only on January 19, 2000. Before that, it was customary for FOMC policy changes to be communicated to market participants through actions rather than words.

There are still people who argue for the efficacy of central bank secrecy in various forms, claiming that surprises are more effective and that even accurate information can be misinterpreted, resulting in undesirable financial market volatility. We think that it is fair to say that these arguments have not been persuasive and that the advocates of policy transparency have won the day. We have been reduced to arguments about the mechanics and exact timing of the release of information. Should the minutes of a meeting be released as soon as physically possible following the meeting, as done by the Bank of England's Monetary Policy Committee; or should there be a modest delay until just after the following meeting, which is the FOMC's practice; or is it acceptable to wait for years, as the European Central Bank is planning to do? Is it necessary or advisable for the head of the interest rate-setting body to hold regularly scheduled news conferences? Should the policymakers be required to appear before legislative bodies to provide descriptions of their decisionmaking processes and justifications for their actions? How public should the inputsforecasts, models, and anecdotes-into interest rate decisions be? All of these questions concern minor issues about the availability of information.

As for general principles, we have now progressed to the point where on September 26, 1999, the Interim Committee of the Board of Governors of the International Monetary Fund issued the Code of Good Practices on Transparency in Monetary and Financial Policies: Declaration and Principles (which we will refer to as the IMF Code). As in the case of other standards and codes promulgated under the auspices of the IMF, ${ }^{1}$ the expectation is that they will be adhered to by all of the countries in the world.

We take the statements in the IMF Code to represent a rough version of the consensus on the value of monetary policy transparency. Paragraph 4 of the IMF Code states:

The case for transparency of monetary and financial policies is based on two main premises. First, the effectiveness of monetary

\footnotetext{
1 The IMF monitors compliance with codes and standards on data dissemination, fiscal transparency, banking supervision, accounting, and auditing that are issued by a variety of international agencies.
} 
and financial policies can be strengthened if the goals and instruments of policy are known to the public and if the authorities can make a credible commitment to meeting them. In making available more information about monetary and financial policies, good transparency practices promote the potential efficiency of markets. Second, good governance calls for central banks and financial agencies to be accountable, particularly where the monetary and financial authorities are granted a high degree of autonomy. ${ }^{2}$

This is a concise statement of the view that the key ingredients for an effective central bank are independence, credibility, transparency, and accountability. Going one step further, there is general agreement that independent, transparent, accountable, and credible central banks are able to deliver better overall policy outcomes. ${ }^{3}$

Many people have concluded that the substantial changes undertaken in the operational framework of central banks over the past decade or more have produced better overall policy outcomes. And there is substantial prima facia evidence to support the case. Looking at a broad array of industrialized, transition, and emerging market economies, we see institutional reforms that have increased both the independence and accountability of central banks and, in addition, made monetary policy more transparent through clear public statement of instruments, methods, and objectives. Not only this, but over the same decade or so, many central banks have succeeded in establishing significant reputations for competence, acquiring considerable credibility in the process.

The data that we study here bear out that, as the institutional framework was evolving, macroeconomic performance was improving. Both the level and variability of inflation were lower over the past five years than they were in the previous ten. Looking at a broad cross-section of 63 countries, we see that median inflation has dropped from 7.04 percent in 1985:Q1-1994:Q4 to 2.97 percent in 1995:Q1-1999:Q4. The decrease in average inflation has been even sharper, going from 83.19 percent to 8.59 percent. Inflation rose in only 10 of the 63 countries, and in the bulk of those the increase was small-only in Ghana, Indonesia, and Turkey did average inflation rise by more than 2 percentage points.

Successful policymaking usually means more than just reducing inflation. It means stabilizing inflation and output as well. Looking at a somewhat narrower sample of 24 countries, we see that 20 experienced lower inflation variability while output variability was lower in $15 .{ }^{4}$ Again, this occurred as the institutional framework for policymaking was changing, suggesting at least the possibility of a relationship.

The remainder of the paper explores the empirical relationship between economic performance and the monetary policy framework. For reasons that will become clear later, the data on transparency, accountability, credibility, and independence force us to study a cross-section of countries. That is, we examine the extent to which contemporaneous differences in institutional design are able to explain the observed variation in performance across countries during a fixed period of time. We are not able to study how changes in the structure of policymaking have affected changes in macroeconomic outcomes.

With the exception of the measure of credibility, our data on the monetary policy framework in each country are from the Bank of England's Center for Central Bank Studies survey of 93 central banks reported in Fry et al. (2000). This survey contains an incredible wealth of information, including measures of the degree of independence, accountability, and transparency of central banks. But Fry et al. (2000) did their survey only once in 1998 (with revisions in 1999), and so that is all that is available.

Our starting point in Section II is the development of measures of macroeconomic performance and monetary policy efficiency. These measures turn out to be related, and we describe how both

\footnotetext{
2 The "Code of Good Practices on Transparency in Monetary and Financial Policies: Declaration and Principles" is available in its entirety at < www.imf.org/external/np/mae/mft/code/index.htm > .

3 Empirical studies by Alesina (1988), Grilli, Masciandaro, and Tabellini (1991), Cukierman (1992), Cukierman, Webb, and Neyapti (1992), and Alesina and Summers (1993), among others, find evidence of a negative correlation of central bank independence with lower and more stable inflation, within industrialized countries. Also, Chortareas, Stasavage, and Sterne (2002) examine the association between the cross-country differences in macroeconomic outcomes and the degree of transparency exhibited by monetary policy, measured by the detail with which central banks publish economic forecasts. Their results suggest that a high degree of transparency in economic forecasts is associated with a lower inflation for all countries (with the exception of the ones that target the exchange rate, for which the publication of forecasts has no significant impact on inflation).

4 See Cecchetti, Flores-Lagunes, and Krause (2002) for details on these calculations.
} 
of them arise from an optimal policy problem. Following our previous work with Flores-Lagunes (Cecchetti, Flores-Lagunes, and Krause, 2002), we measure performance as a weighted average of output and inflation variability, while our measure of policy efficiency (or inefficiency) is related to the distance of the economy's performance point to the inflation-output variability frontier.

In Section III we discuss how we measure the credibility of monetary policy. This is clearly a difficult undertaking and there are a number of possible ways to proceed. One possibility would be to use surveys or press reports to examine what people think about the actions of central bankers. But since we study a large number of countries, collecting such data is an almost impossible task. Instead, we have adopted the view that credibility comes from what you do, not what you say or what someone else says about it. This premise led us to measure credibility by looking at past inflation performance, and here we define a credible central bank as one that has successfully delivered low inflation.

The remainder of the paper puts all of these pieces together and looks for correlations among them. This is the subject of Section IV, and our findings are somewhat discouraging. In the end, we conclude that credibility trumps virtually everything else: countries with a history of high inflation exhibit comparatively worse macroeconomic and policy performance, regardless of the framework in which their central banks operate.

\section{MEASURING MACROECONOMIC PERFORMANCE AND EFFICIENCY OF MONETARY POLICY}

Following Cecchetti et al. (2002), we derive measures of macroeconomic performance and policy efficiency using the inflation-output variability trade-off, or efficiency frontier. To obtain these measures, we first summarize how Cecchetti et al. perform the theoretical derivation and then proceed to briefly describe the estimation method used in constructing the measures. Finally, we report the results on macroeconomic performance and policy efficiency loss for the period of 1991:Q1-1998:Q4.

\section{Theoretical Derivation of the Measures}

The measures of interest can be derived using a two-dimensional graph, and so we begin with a simple intuitive explanation. The concept of an inflation-output variability frontier is easiest under-

\section{Figure 1}

\section{Efficiency Frontier and Performance Point}

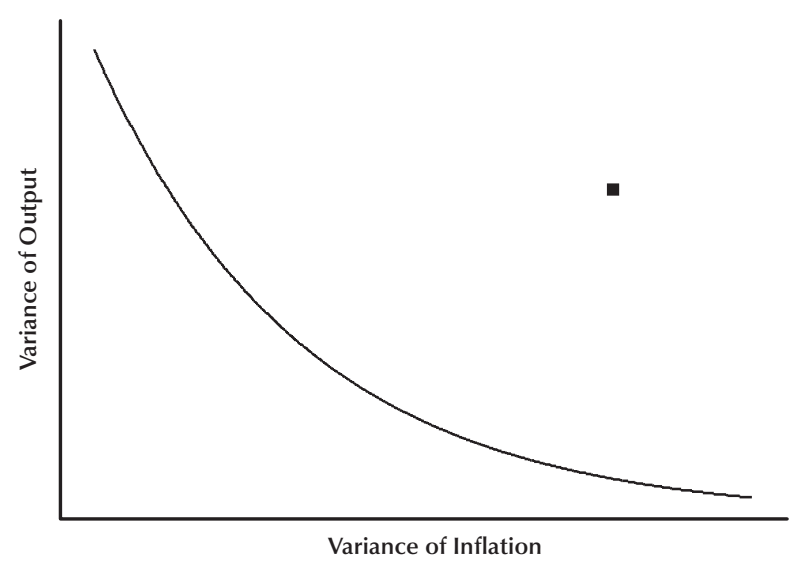

stood by considering a simple economy that is affected by two general types of disturbances, both of which may require policy responses. These are aggregate demand shocks - which move output and inflation in the same direction-and aggregate supply shocks-which move output and inflation in opposite directions. Since monetary policy can move output and inflation in the same direction, it can completely offset the effect of aggregate demand shocks. By contrast, aggregate supply shocks will force the monetary authority to face a trade-off between the variability of output and that of inflation. ${ }^{5}$

This trade-off allows us to construct an efficiency frontier for monetary policy that traces the points of minimum inflation and output variability. This is the curved line in Figure 1, known in the literature as the Taylor curve (Taylor, 1979). The location of the efficiency frontier depends on the variability of aggregate supply shocks - the smaller such variability, the closer the frontier will be to the origin. If monetary policy is optimal, the economy will be on this curve. The location of the economy on the frontier depends on the policymaker's preferences for inflation and output stability.

When policy is suboptimal, the economy will not be on this frontier. Instead, the performance point will be up and to the right, with inflation and output variability both in excess of other feasible points. Movements of the performance point toward the

\footnotetext{
5 For a simple algebraic model and a discussion of the derivation of the output-inflation variability frontier, see Cecchetti and Ehrmann (2001).
} 


\section{Figure 2}

\section{Derivation of the Optimal Variances}

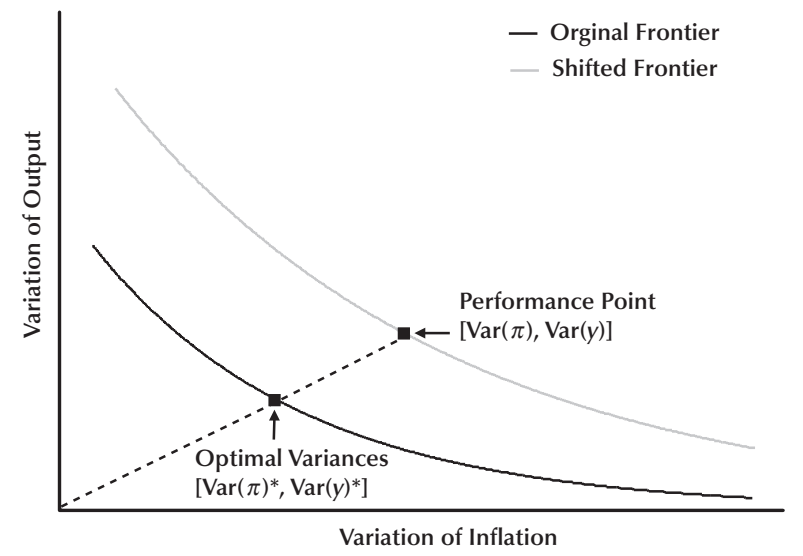

frontier are an indication of improved policymaking.

We require measures of an economy's performance, in terms of output and inflation variability, as well as the distance of that point from the efficiency frontier. To compute these, we assume that the objective of the central banker is to minimize a weighted sum of inflation and output variability. This is the standard quadratic loss function used in most contemporary analyses of central bank policy. We can summarize this loss through the following specific representation:

$$
\text { Loss }=\lambda \operatorname{Var}(\pi)+(1-\lambda) \operatorname{Var}(y), 0 \leq \lambda \leq 1,
$$

where $\pi$ is inflation, $y$ is output, and $\lambda$ is the policymaker's preference parameter-Cecchetti and Ehrmann (2001) call this the policymaker's inflation variability aversion.

But measuring the loss associated with a particular performance point requires that we have an estimate of the preference parameter, $\lambda$. Our approach is to consider a set of plausible values of $\lambda$ for each of the analyzed countries based on the estimates obtained elsewhere by Cecchetti and Ehrmann (2001) and Krause (2002). This procedure means that we do not have to identify a single value of this parameter for each individual country. In the following section, we show that our results are robust to this choice. With this in mind, we set $\lambda$ equal to 0.8 for all countries, with the exception of Israel, Mexico, Chile, and Greece, for which we choose a value of 0.3 . These four countries experienced very high levels of inflation during the 1980s, suggesting that inflation variability must have had a much lower weight in the policymaker's loss function.

Before we proceed with describing the measure of policy efficiency, we need to discuss how we derive the optimal variances of output and inflation. Beginning with Figure 1, we shift the efficiency trade-off homothetically outward until it passes through the performance point representing the observed variances of inflation and output. Figure 2 shows the original and shifted frontiers. Graphically, the optimal variances are at the intersection of the original frontier with a line from the origin to the performance point. Cecchetti et al. show with more detail how to derive these variances analytically.

We can now define the measures of performance and policy efficiency that we will use in our empirical computations. To compute macroeconomic performance, we combine the observed variances of output and inflation together to construct a single measure of stability. We define performance, $P$, as

$$
P=\lambda \operatorname{Var}(\pi)+(1-\lambda) \operatorname{Var}(y) .
$$

The lower $P$, the more stable the economy.

We gauge monetary policy efficiency by looking at how close the actual performance is to the performance under optimal policy. Policy inefficiency is measured by

(3)

$$
E=\lambda\left[\operatorname{Var}(\pi)-\operatorname{Var}(\pi)^{*}\right]+(1-\lambda)\left[\operatorname{Var}(y)-\operatorname{Var}(y)^{*}\right] \text {, }
$$

where $\operatorname{Var}(\pi)^{*}$ and $\operatorname{Var}(y)^{*}$ are the variances of inflation and output under optimal policy, respectively. The more efficient policymakers are at implementing the optimal policy, the closer $E$ will be to zero.

\section{Estimating the Efficiency Frontier}

As we described above, in Cecchetti et al. we construct an efficiency frontier for the countries in the sample in order to compute macroeconomic performance and policy efficiency loss. The basic procedure is as follows. Beginning with the quadratic loss function representing trade-offs among combinations of inflation and output variability, we treat policy as a solution to a control problem in which the interest rate path is chosen to place the economy at the point on the variability frontier that minimizes the loss. Formally, we compute the policy reaction function that minimizes the loss, subject to the constraint that is imposed by the structure of the 
economy. For a given loss function, with a particular weighting of inflation and output variability, we are able to plot a single point on the efficiency frontier. As we change the relative weight assigned to the variance of inflation and output in the loss function, we are able to trace out the entire efficiency frontier.

Our econometric procedure has two main steps. First, we estimate simple structural models of inflation and output for each of the 24 countries in our sample. Next, we describe the construction of the efficiency frontier from the model estimates. This will allow us to compute the macroeconomic performance and policy efficiency loss.

We consider linear two-equation systems for each country based on a dynamic aggregate demand/ aggregate supply model. The basic model consists of the following two equations:

$$
\begin{gathered}
y_{t}=\sum_{l=1}^{2} \alpha_{1 l} i_{t-l}+\sum_{l=1}^{2} \alpha_{1(l+2)} y_{t-l} \\
+\sum_{l=1}^{2} \alpha_{1(l+4)} \pi_{t-1}+\alpha_{17} x_{t-1}+\varepsilon_{1 t} \\
\text { (5) } \pi_{t}=\sum_{l=1}^{2} \alpha_{21} y_{t-1}+\sum_{l=1}^{2} \alpha_{2(l+2)} \pi_{t-1}+\alpha_{25} x_{t-1}+\varepsilon_{2 t} .
\end{gathered}
$$

The first equation represents an aggregate demand curve. It relates (demeaned and detrended) log industrial production, $y$, to two of its own lags; to two lags of the nominal interest rate, $i$; to two lags of demeaned inflation, $\pi$; and to one lag of demeaned external price inflation, $x$. The second equation is an aggregate supply curve. Here, inflation is assumed to be a function of two of its own lags, representing inflation expectations, two lags of (demeaned and detrended) log industrial production, and one lag of demeaned external price inflation. The error terms $\varepsilon_{1}$ and $\varepsilon_{2}$ are assumed to be mean zero and constant variance.

We estimate equations (4) and (5) for each country separately using ordinary least squares. ${ }^{6}$ The Durbin $\mathrm{h}$ test allows us to determine whether additional lags of the variables were required to correct for autocorrelation. ${ }^{7}$ In some cases we also include dummy variables to account for currency crises, sharp recessions, or structural changes.

The next step consists of employing the estimated model to construct the efficiency frontier. We assume that the policymaker's objective is to minimize an objective function (given by the loss function in (1)) subject to the constraints imposed by the dynamic structure of the economy given by equations (4) and (5). This optimization allows us to obtain a pair of optimal variances of inflation and output for a given value of $\lambda$. By varying the $\lambda$ over the interval $[0.001,0.999]$ with an increment of 0.001 , we are able to trace out an entire frontier similar to the one in Figure 1.

Finally, given the values chosen for $\lambda$ and the optimal variances for each country, we can compute the measures of interest.

\section{Estimates of Macroeconomic Performance and Policy Efficiency Loss}

We now look at the estimates of performance and efficiency loss for the 24 countries in the Cecchetti et al. study, using data for 1991:Q11998:Q4. The results are plotted in Figures 3A and $3 \mathrm{~B}$ and the estimates of the measures are reported in Table A1 in the appendix. ${ }^{8}$ For each country, the vertical height of the bar measures the performance loss, $P$. This is divided into two portions: (i) the minimal performance loss, which measures what would be attained if the economy were on its inflationvariability frontier, and (ii) the remainder, which measures policy inefficiency. The differences in scale require that we divide the countries into two groups: those with relatively stable performance in Figure $3 \mathrm{~A}$ and those with higher output and inflation variability in Figure 3B.

Overall, the results suggest that there is high variation in both performance and policy efficiency. The Netherlands, for example, has the lowest value for both $P$ and $E$, while Israel has the most inefficient policymakers and most volatile economy. There are also cases between these, such as Finland, where policy is efficient but the economy is relatively

6 Since we are estimating a system of two equations separately, there might exist some cross-correlation between the error terms of the equations that can be exploited to obtain more efficient estimators with a system estimator such as seemingly unrelated regressions (SUR). To check whether the separate estimation of each equation is efficient relative to system estimation, we tested the contemporaneous correlation of the error terms of the two-equation model for each period in each of the countries in our sample. We were not able to reject the null hypothesis of zero contemporaneous correlation at a 10 percent level or higher in both periods for all countries with the exception of two. Still, in neither of these two cases are the SUR coefficients and standard errors significantly different from the ones obtained through the OLS estimation.

7 We tested for nonstationarity of the error terms in both equations using the Phillips-Perron test. We were able to reject the null hypothesis of nonstationarity at the 1 percent significance level in all countries for both subperiods.

8 Both the performance loss and efficiency measure have been scaled up by a factor of 100 . 


\section{Figure 3}

\section{Macroeconomic Performance Loss}

A.

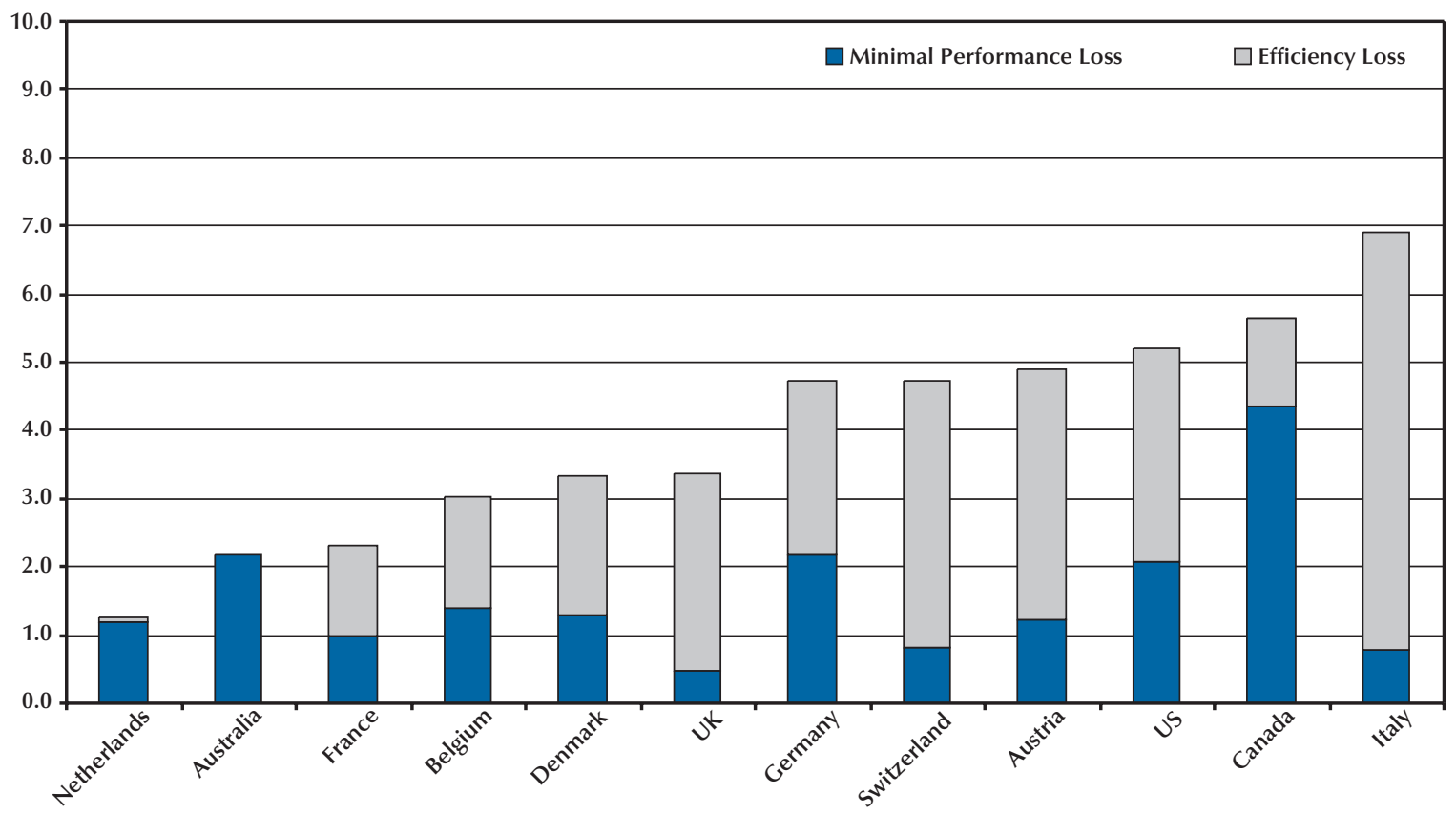

B.

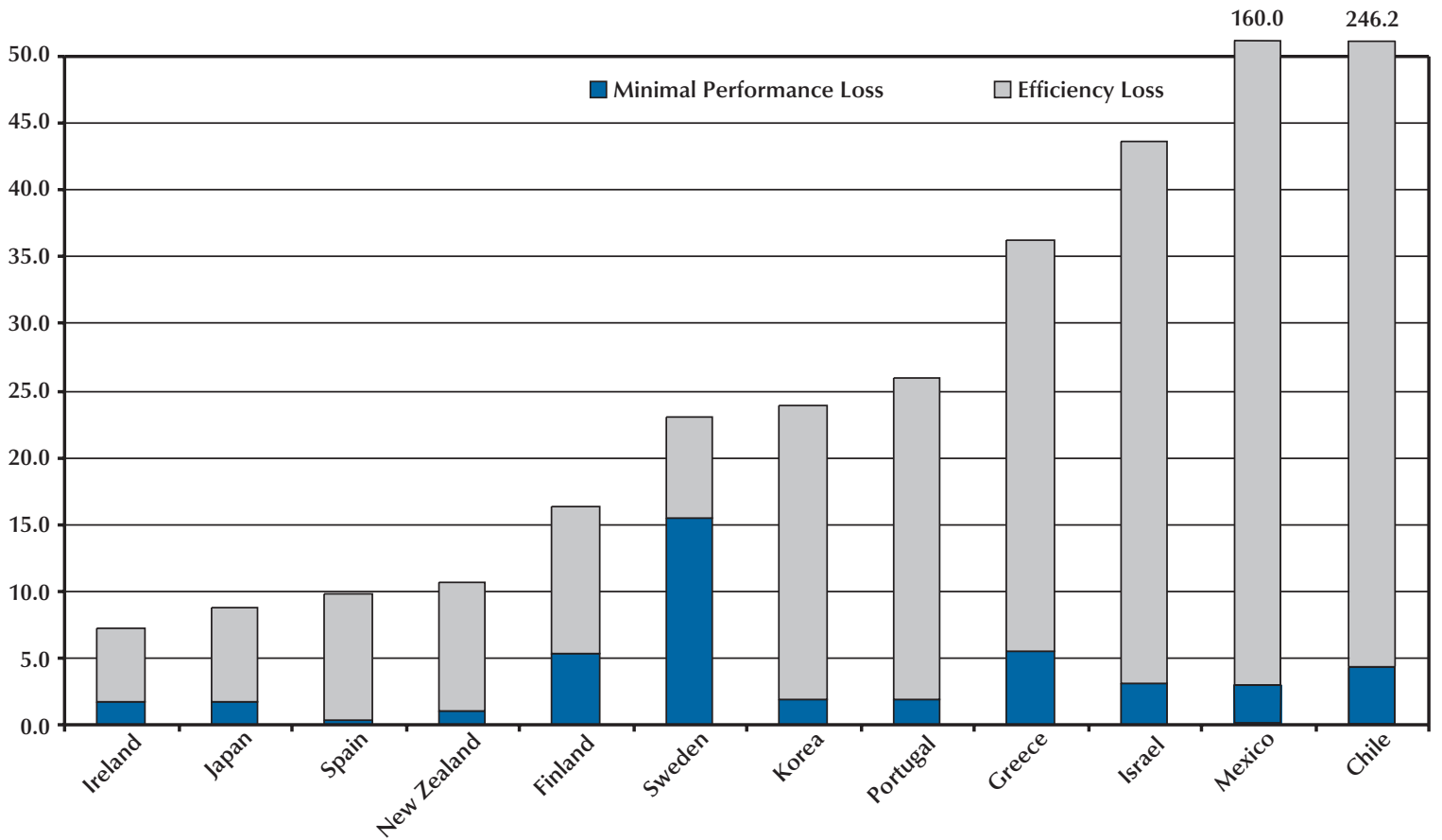


unstable, and Switzerland, where performance is good but policy is not. ${ }^{9}$

Our goal is to examine whether the crosssectional variation in these measures of performance and policy efficiency can be explained by differences in central bank independence, accountability, transparency, and credibility. Before undertaking this task, we need to describe the data on monetary policy framework variables, which we do in the following section.

\section{MEASURES OF MONETARY FRAMEWORK CHARACTERISTICS}

In order to relate macroeconomic performance and policy efficiency to central bank features, we require quantitative measures of the several institutional characteristics of the central bank. For this purpose we employ the measures of central bank independence, accountability, and transparency derived by Fry et al. (2000) and based on survey information. We first describe these and then proceed to discuss our construction of a measure of policy credibility that is based on past inflation performance. ${ }^{10}$

\section{Central Bank Independence}

Fry et al. construct a weighted index for independence by studying the responses to five questions on their survey. These questions look at the following elements: how important is price stability as an objective; how important is the role of the central bank in choosing the levels of the target variable (goal independence) and the policy instrument (instrument independence); to what extent does the government rely on central bank financing; and how long is the term of office of the governor/chairman?

\section{Central Bank Accountability}

The Fry et al. survey looks at two main forms of accountability. First, it asks whether the policy contract between the government and the central bank incorporates a numerical target for the goal variable, what the role of the government is in setting this target, and which procedures take place if the target is missed. Second, accountability measures how the government and parliament monitor the central bank. The index of accountability is constructed by taking the average of these two measures.

\section{Central Bank Transparency}

To derive a measure of transparency or policy explanations, Fry et al. look at the responses to the degree and frequency at which each central bank provides reports on its policy decisions, assessments about the state of the economy, and public explanations of forecasts. The index of transparency is obtained as a simple average of these three criteria.

\section{Central Bank Credibility}

We now turn to the derivation of the credibility index. Cukierman and Meltzer (1986) define monetary policy credibility as "the absolute value of the difference between the policymaker's plans and the public's beliefs about those plans." 11 The further realized inflation is from the announced target level, the less credible is the policymaker. If the monetary authority has an explicit inflation target, credibility can be measured by the distance from the expected inflation to the target (Svensson, 1999).

Consistent with these suggestions, we construct an index of policy credibility that takes into account the deviations of expected inflation from the central bank's target level. In order to normalize this index between 0 and 1 , we define it as

(6)

$$
I C=\left\{\begin{array}{ll}
1 & \text { if } E(\pi) \leq \pi^{t} \\
1-\frac{1}{0.2-\pi^{t}}\left(E(\pi)-\pi^{t}\right) & \text { if } \pi^{t}<E(\pi)<20 \% \\
0 & \text { if } E(\pi) \geq 20 \%
\end{array}\right\} .
$$

The index of credibility takes a value of 1 if expected annual inflation is less than or equal to the target level of inflation, $\pi_{t}$, and it decreases linearly as expected inflation rises. If expected inflation is greater than 20 percent, we assign the index a value of 0 .

Finally, to compute this index we assume that the target level for inflation is equal to 2 percent for all countries and we proxy $E(\pi)$ as the average realized inflation for the period between 1985:Q1 and 1989:Q4 for all 63 countries in our sample. The data on the index of credibility is presented in Table A2 in the appendix.

\section{EMPIRICAL RESULTS}

We now turn to an examination of all of the information on performance, efficiency, and insti-

\footnotetext{
9 For a more detailed discussion of these results, as well as an examination of changes in performance and policy efficiency over time, see Cecchetti et al. (2002)

${ }^{10}$ We report the values of these indices in Table $\mathrm{A} 2$ in the appendix.

${ }^{11}$ Cukierman and Meltzer (1986, p. 1108)
} 
Table 1

Performance, Efficiency, and Monetary Policy Framework (Correlation Coefficients)

\begin{tabular}{lccc} 
& $\begin{array}{c}\text { Average inflation } \\
\mathbf{( 1 9 9 5 - 9 9 )}\end{array}$ & $\begin{array}{c}\text { Macro performance } \\
(\mathbf{1 9 9 0 - 9 7 )}\end{array}$ & $\begin{array}{c}\text { Policy inefficiency } \\
\mathbf{( 1 9 9 0 - 9 7 )}\end{array}$ \\
\hline Independence & $-0.129(0.17)$ & $0.072(0.74)$ & $0.055(0.80)$ \\
Accountability & $-0.093(0.48)$ & $0.019(0.93)$ & $0.012(0.96)$ \\
Transparency & $-0.349(0.04)$ & $-0.254(0.24)$ & $-0.257(0.24)$ \\
Credibility & $-0.571(0.00)$ & $-0.757(0.00)$ & $-0.753(0.00)$
\end{tabular}

NOTE: Better macroeconomic performance and more efficient policy are identified with values closer to zero, while higher independence, accountability, transparency, and credibility are identified with higher values. The heteroskedasticity-corrected $p$ values are in parentheses.

tutional structure. We expect that countries with more independent, transparent, accountable, and credible central banks will in general exhibit better macroeconomic outcomes. We take this hypothesis to the data and consider the relationships between macroeconomic performance (as measured by $P$ and by average inflation) and policy efficiency (measured by $E$ and by policy framework variables described in the previous section). We look at both simple correlations and multivariate analysis.

\section{Simple Correlations}

Table 1 displays the simple correlations among the four indices of central bank framework and our measures of macroeconomic performance and policy efficiency, as well as average inflation for the period of 1995:Q1-1999:Q4.

First, we observe that there is a positive correlation between central bank independence and the performance and efficiency loss measures, while for the broader cross-section of countries independence is negatively correlated with average inflation. This relationship has been extensively documented for industrialized countries, and it is still present when considering transition and developing economies. Nevertheless, none of these correlations is significantly different from zero at even the 10 percent level.

Proceeding down the table, we see that the index of central bank accountability is negatively correlated with average inflation and positively correlated with performance and efficiency loss. But as with the case of independence, neither of these correlations is significant, suggesting that this particular characteristic of the monetary framework, at least by itself, does not play a crucial role in explaining the cross-country differences in inflation, performance, and policy efficiency.
Looking at the one-dimensional relationship with transparency, we see that all of the correlations are negative. The result for average inflation is also significantly different from zero at the 5 percent level. Furthermore, our point estimate of -0.35 in this case is basically indistinguishable from the correlation between average log inflation and the alternative (Guttman) index of transparency reported in Chortareas, Stasavage, and Sterne (2002). ${ }^{12}$

Finally, we find that the correlation between the index of credibility and the three outcome measures is negative and significant at the 1 percent level. This is our most clear result. Countries that maintained low inflation in the past are expected to exhibit lower current inflation and less variable inflation and output. Good policymaking is positively serially correlated.

\section{Multivariate Analysis}

We now turn to a simple multivariate analysis. Table 2 reports the results of regressing, simultaneously, average inflation, macroeconomic performance, and policy efficiency on the four monetary framework variables and compares these results with the ones arising from excluding the credibility index as an explanatory variable. All three regressions are dominated by the presence of the credibility measure, which enters with a negative coefficient and is estimated very precisely. ${ }^{13}$ The coefficients

\footnotetext{
12 Chortareas, Stasavage, and Sterne (2002) also use a larger data set, which includes 87 countries.

${ }^{13}$ This result is even sharper when we use the data on average inflation for the period 1990:Q1-1994:Q4 to construct the index of credibility. Under these circumstances, both the $\mathrm{R}^{2}$ and the coefficients associated with credibility rise, giving further support to the argument that countries with high past inflation exhibit poor performance regardless of their framework.
} 


\section{Table 2}

\section{Performance, Efficiency, and Monetary Policy Framework (Regression Results)}

\begin{tabular}{lccccrr} 
& \multicolumn{2}{c}{$\begin{array}{c}\text { Average inflation } \\
\mathbf{( 1 9 9 5 - 9 9 )}\end{array}$} & \multicolumn{2}{c}{$\begin{array}{c}\text { Macro performance } \\
(\mathbf{1 9 9 0 - 9 7 )}\end{array}$} & \multicolumn{2}{c}{$\begin{array}{c}\text { Policy inefficiency } \\
\mathbf{( 1 9 9 0 - 9 7 )}\end{array}$} \\
\hline Intercept & $0.289(0.00)$ & $0.222(0.01)$ & $0.439(0.63)$ & $0.514(0.73)$ & $0.545(0.55)$ & $0.619(0.67)$ \\
Independence & $0.003(0.97)$ & $0.026(0.74)$ & $0.970(0.38)$ & $-0.059(0.97)$ & $0.803(0.47)$ & $-0.206(0.90)$ \\
Accountability & $-0.062(0.28)$ & $-0.030(0.60)$ & $0.478(0.37)$ & $0.313(0.72)$ & $0.479(0.38)$ & $0.318(0.71)$ \\
Transparency & $-0.108(0.23)$ & $-0.217(0.05)$ & $-0.444(0.17)$ & $-0.563(0.29)$ & $-0.462(0.16)$ & $-0.579(0.27)$ \\
Credibility & $-0.172(0.00)$ & & $-1.405(0.00)$ & & $-1.378(0.00)$ & 0.665 \\
$\mathrm{R}^{2}$ & 0.364 & 0.121 & 0.677 & 0.072 & 22 & 0.073 \\
No. of observations & 60 & 60 & 22 & 22 & 22
\end{tabular}

NOTE: Better macroeconomic performance and more efficient policy are identified with values closer to zero, while higher independence, accountability, transparency, and credibility are identified with higher values. The heteroskedasticity-corrected $p$ values are in parentheses.

on the remaining three regressors are negative in only four of the nine cases, and they are all estimated very imprecisely, as indicated by the relatively high $p$ values reported in Table 2 . If we drop the credibility measure from the specification, then we observe, as expected, a sharp drop in the goodness of fit. The other variables remain insignificant, with the exception of transparency, which enters the regression of average inflation on the framework variables with a negative sign and a significant (to the 5 percent level) coefficient. These results provide further evidence supporting the view that central bank credibility - represented by past inflation performance-is the main determinant of current macroeconomic performance and policy efficiency. ${ }^{14}$

Since our results suggest that credibility and, to a somewhat lesser extent, transparency are the two factors that explain most of the cross-country variation in macroeconomic outcomes, it is interesting to ask how large the impact is. To address this, we calculate the extent to which changes in the levels of transparency and credibility translate into lower average inflation. That is, we find the inflation that would have had to take place (as a deviation from 2 percent) after these changes, holding output variation in the loss function constant. For the case of Spain, an increase in transparency from 0.59 to the sample median, 0.79 , is equivalent to a drop of 0.53 percentage points in average inflation. An increase in credibility for the United Kingdom from 0.82 to 0.91 percentage points (estimated value for the United States and France) would represent a drop in average inflation of 1.19 percentage points.

\section{Interpreting the Results}

Our findings suggest that credibility is the primary factor explaining the cross-country variation in macroeconomic outcomes, trumping the contribution of the other framework variables. This result is consistent with Jensen's (2000) argument that a committed (i.e., credible) central bank will not necessarily provide economic agents with substantial information about the behavior of instruments and targets. He derives an optimal level of transparency, which will depend on the initial credibility of the bank and the amount of information available to the agents. The model suggests that a high degree of transparency need not always be an advantage to the central bank.

On the other hand, it is reasonable to believe that independence, accountability, and transparency actually lead to increased central bank credibility. Given that we lack a time-series for the data on the policy framework, we are unable to examine this claim head on. All we can do is see whether credibility is highly correlated with accountability, independence, and transparency. We find that credibility and transparency have a correlation of 0.31 , but that credibility is virtually uncorrelated with the measures of accountability and independence.

Looking back at the performance and efficiency

\footnotetext{
${ }^{14}$ We also tested whether the policy framework variables were associated with the cross-country differences in the sacrifice ratio (which we approximate using the estimated efficiency frontier for 24 countries), but we failed to find any significant relationship.
} 
measures plotted in Figure 3B, we see that Chile and Mexico are substantial outliers. This naturally leads us to ask whether our results are dominated by these two countries. Deleting them from the sample, we find that the general character of the results is largely unchanged. While coefficients on the other framework variables remain statistically insignificant, the coefficient associated with the credibility index changes from -1.405 to -0.429 in the macroeconomic performance regression (with the $\mathrm{R}^{2}$ actually increasing from 0.677 to 0.811 ) and from -1.378 to -0.386 in the policy efficiency regression (with the $\mathrm{R}^{2}$ rising from 0.665 to 0.852 ). The coefficients still remain significant at the 1 percent level.

\section{CONCLUSIONS}

This paper explores the empirical relationships between economic outcomes and the monetary policy framework. Our findings suggest that a better macroeconomic performance and more efficient policy are present in more credible and, to some extent, more transparent central banks. Independence and accountability, to the extent that we are able to measure them, do not seem to explain much of the cross-country variation in macroeconomic outcomes, either individually or in conjunction with other variables. Further exploration of the relationship of macroeconomic performance awaits new time-series data.

\section{REFERENCES}

Alesina, Alberto. "Macroeconomics and Politics," Stanley Fisher, ed., NBER Macroeconomics Annual. Cambridge, MA: MIT Press, 1988.

and Summers, Lawrence H. "Central Bank Independence and Macroeconomic Performance: Some Comparative Evidence." Journal of Money, Credit, and Banking, May 1993, 25(2), pp. 151-62.

Cecchetti, Stephen G. and Ehrmann, Michael. "Does Inflation Targeting Increase Output Volatility? An International Comparison of Policymakers' Preferences and Outcomes," in Norman Loayza and Klaus Schmidt-Hebbel, eds., Monetary Policy: Rules and Transmission Mechanisms, No. 4 in the Series on Central Banking, Analysis and Economic Policies. Santiago, Chile: Central Bank of Chile, 2001, pp. 247-74.

; Flores-Lagunes, Alfonso and Krause, Stefan.
"Has Monetary Policy Become More Efficient? A CrossCountry Analysis.” Unpublished manuscript, 2002.

Chortareas, Georgios; Stasavage, David and Sterne, Gabriel. "Does it Pay To Be Transparent? International Evidence from Central Bank Forecasts." Federal Reserve Bank of St. Louis Review, July/August 2002, 84(4), pp. 99-118.

Cukierman, Alex. Central Bank Strategy, Credibility and Independence: Theory and Evidence. Cambridge, MA: MIT Press, 1992.

"Central Bank Independence and Monetary Control.” The Economic Journal, November 1994, 104, pp. $1437-48$

and Meltzer, Allan H. "A Theory of Ambiguity, Credibility, and Inflation under Discretion and Asymmetric Information." Econometrica, September 1986, 54(5), pp. 1099-128.

; Webb, Steven B. and Neyapti, Bilin. "Measuring the Independence of Central Bank and Its Effect on Policy Outcomes." World Bank Economic Review, September 1992, 6(3), pp. 353-98.

Fry, Maxwell; Julius, DeAnne; Mahadeva, Lavan; Roger, Sandra and Sterne, Gabriel. "Key Issues in the Choice of Monetary Policy Framework," in Lavan Mahadeva and Gabriel Sterne, eds., Monetary Policy Frameworks in a Global Context. London: Routledge (Bank of England), 2000.

Grilli, Vittorio, Masciandaro, Donato and Tabellini, Guido. "Political and Monetary Institutions and Public Financial Policies in the Industrial Countries." Economic Policy: $A$ European Forum, October 1991, 6(2), pp. 341-92.

Jensen, Hans E. "Optimal Degrees of Transparency in Monetary Policymaking.” Working paper, University of Copenhagen, 2000.

Krause, Stefan. "Measuring Monetary Policy Efficiency in European Union Countries.” Unpublished manuscript, 2002.

Svensson, Lars E.O. "How Should Monetary Policy Be Conducted in an Era of Price Stability?" Prepared for the symposium New Challenges for Monetary Policy, Federal Reserve Bank of Kansas City, 26-28 August 1999.

Taylor, John B. "Estimation and Control of a Macroeconomic Model with Rational Expectations." Econometrica, September 1979, 47(5), pp. 1267-86. 


\section{Appendix}

Table A1 presents the estimates for the measures of macroeconomic performance and policy inefficiency obtained by Cecchetti et al. (2002).

Table A2 reports the data on inflation and the monetary policy framework variables. Average inflation is obtained from the simple mean of quarterly data of consumer price index (CPI) inflation for the period 1995:Q1-1999:Q4, from the IFS statistics. The data for the indices used for indepen- dence and accountability are obtained from the weighted total scores in Tables A.5 and A.6 of Fry et al. (2000), respectively, while transparency is measured using the unweighted total score for explaining policy, presented in Table A.7 of Fry et al. Finally, the index of policy credibility is constructed as specified in Section III, using the average CPI inflation for the period between 1985:Q1 and 1989:Q4, from the IFS statistics.

\section{Table A1}

Macroeconomic Performance and Monetary Policy Inefficiency

\begin{tabular}{|c|c|c|}
\hline Country & Macro performance (1991-98) & Policy inefficiency (1991-98) \\
\hline Australia & 0.0217 & 0.0001 \\
\hline Austria & 0.0491 & 0.0369 \\
\hline Belgium & 0.0301 & 0.0161 \\
\hline Canada & 0.0566 & 0.0130 \\
\hline Chile & 2.4625 & 2.4188 \\
\hline Denmark & 0.0333 & 0.0202 \\
\hline Finland & 0.1630 & 0.1103 \\
\hline France & 0.0232 & 0.0134 \\
\hline Germany & 0.0473 & 0.0254 \\
\hline Greece & 0.3620 & 0.3062 \\
\hline Ireland & 0.0716 & 0.0551 \\
\hline Israel & 0.4360 & 0.4048 \\
\hline Italy & 0.0689 & 0.0610 \\
\hline Japan & 0.0880 & 0.0707 \\
\hline Korea & 0.2383 & 0.2200 \\
\hline Mexico & 1.6003 & 1.5711 \\
\hline Netherlands & 0.0127 & 0.0008 \\
\hline New Zealand & 0.1059 & 0.0957 \\
\hline Portugal & 0.2598 & 0.2413 \\
\hline Spain & 0.0971 & 0.0930 \\
\hline Sweden & 0.2311 & 0.0757 \\
\hline Switzerland & 0.0473 & 0.0391 \\
\hline UK & 0.0338 & 0.0292 \\
\hline US & 0.0521 & 0.0313 \\
\hline Average & 0.2747 & 0.2479 \\
\hline
\end{tabular}

NOTE: Better macroeconomic performance and more efficient policy are identified with values closer to zero. 


\section{Table A2}

\section{Average Inflation and Policy Framework Variables}

\begin{tabular}{|c|c|c|c|c|c|}
\hline Country & $\begin{array}{l}\text { Average inflation } \\
(\%)(1995-99)\end{array}$ & $\begin{array}{c}\text { Index of } \\
\text { independence }\end{array}$ & $\begin{array}{c}\text { Index of } \\
\text { accountability }\end{array}$ & $\begin{array}{c}\text { Index of } \\
\text { transparency }\end{array}$ & $\begin{array}{c}\text { Index of } \\
\text { credibility }\end{array}$ \\
\hline Argentina & 0.77 & 0.79 & 1.00 & 0.53 & 0.00 \\
\hline Australia & 1.97 & 0.73 & 0.83 & 0.78 & 0.68 \\
\hline Austria & 1.38 & 0.68 & 0.67 & 0.27 & 0.99 \\
\hline Bahamas & 1.32 & 0.39 & 1.00 & 0.50 & 0.83 \\
\hline Bahrain & 1.08 & 0.54 & 0.75 & 0.18 & 1.00 \\
\hline Barbados & 2.46 & 0.24 & 0.92 & 0.73 & 0.89 \\
\hline Belgium & 1.45 & 0.77 & 0.33 & 0.68 & 0.98 \\
\hline Belize & 1.66 & 0.43 & 0.42 & 0.48 & 0.97 \\
\hline Canada & 1.61 & 0.91 & 1.00 & 0.79 & 0.87 \\
\hline Chile & 6.04 & 0.93 & 0.17 & 0.83 & 0.00 \\
\hline China, P.R. & 5.20 & 0.68 & 1.00 & 0.63 & 0.28 \\
\hline Croatia & 4.53 & 0.79 & 0.83 & 0.42 & 0.00 \\
\hline Cyprus & 2.62 & 0.77 & 0.58 & 0.48 & 0.93 \\
\hline Denmark & 2.15 & 0.88 & 0.75 & NA & 0.87 \\
\hline Eastern Caribbean & 2.17 & 0.49 & 0.92 & 0.48 & 0.98 \\
\hline Ecuador & 33.14 & 0.93 & 0.75 & 0.59 & 0.00 \\
\hline Egypt & 7.09 & 0.53 & 0.83 & 0.47 & 0.06 \\
\hline Fiji & 3.26 & 0.73 & 0.17 & 0.64 & 0.78 \\
\hline Finland & 1.07 & 0.91 & 0.92 & 0.74 & 0.84 \\
\hline France & 1.24 & 0.90 & 0.83 & 0.53 & 0.91 \\
\hline Germany & 1.31 & 0.96 & 0.17 & 0.70 & 1.00 \\
\hline Ghana & 32.44 & 0.60 & 0.58 & 0.36 & 0.00 \\
\hline Greece & 6.02 & 0.86 & 0.33 & 0.36 & 0.16 \\
\hline Hungary & 18.85 & 0.86 & 0.83 & 0.49 & 0.51 \\
\hline Iceland & 2.13 & 0.59 & 0.92 & 0.65 & 0.00 \\
\hline India & 8.89 & 0.83 & 0.67 & 0.75 & 0.68 \\
\hline Indonesia & 21.03 & 0.66 & 0.83 & 0.83 & 0.73 \\
\hline Ireland & 1.95 & 0.87 & 0.83 & 0.78 & 0.90 \\
\hline Israel & 8.22 & 0.66 & 1.00 & 0.68 & 0.00 \\
\hline Italy & 2.97 & 0.88 & 0.58 & 0.81 & 0.77 \\
\hline Jamaica & 14.19 & 0.39 & 0.42 & 0.65 & 0.33 \\
\hline Japan & 0.41 & 0.93 & NA & 0.89 & 1.00 \\
\hline Jordan & 3.39 & 0.74 & 0.75 & 0.60 & 0.72 \\
\hline Kenya & 6.06 & 0.66 & 0.67 & 0.52 & 0.56 \\
\hline Korea & 4.42 & 0.73 & 0.83 & 0.88 & 0.88 \\
\hline Kuwait & 2.01 & 0.63 & 0.67 & 0.38 & 1.00 \\
\hline Malaysia & 3.92 & 0.75 & 0.67 & 0.71 & 1.00 \\
\hline Malta & 2.82 & 0.83 & 0.83 & 0.67 & 1.00 \\
\hline Mauritius & 6.63 & 0.70 & 0.33 & 0.20 & 0.77 \\
\hline
\end{tabular}




\section{Table A2 cont'd}

Average Inflation and Policy Framework Variables

\begin{tabular}{lccccc} 
Country & $\begin{array}{c}\text { Average inflation } \\
\text { (\%) }\end{array}$ & $\begin{array}{c}\text { (1995-99) } \\
\text { independence }\end{array}$ & $\begin{array}{c}\text { Index of } \\
\text { accountability }\end{array}$ & $\begin{array}{c}\text { Index of } \\
\text { transparency }\end{array}$ & $\begin{array}{c}\text { Index of } \\
\text { credibility }\end{array}$ \\
\hline Mexico & 24.67 & 0.82 & 0.92 & 0.69 & 0.00 \\
Namibia & 8.33 & 0.50 & 0.33 & 0.56 & 0.36 \\
Netherlands & 2.06 & 0.91 & 0.83 & 0.79 & 1.00 \\
New Zealand & 1.68 & 0.89 & 1.00 & 0.92 & 0.48 \\
Nigeria & 26.08 & 0.42 & 0.92 & 0.37 & 0.00 \\
Norway & 2.18 & 0.57 & 0.50 & 0.89 & 0.75 \\
Peru & 8.41 & 0.89 & 0.92 & 0.38 & 0.00 \\
Poland & 16.47 & 0.86 & 0.58 & 0.69 & 0.00 \\
Portugal & 2.90 & 0.85 & 0.83 & 0.78 & 0.41 \\
South Africa & 7.34 & 0.85 & 0.75 & 0.70 & 0.24 \\
Sierra Leone & 27.53 & 0.62 & 0.83 & 0.47 & 0.00 \\
Singapore & 0.97 & 0.90 & 0.25 & $N A$ & 1.00 \\
Spain & 2.87 & 0.80 & 0.83 & 0.59 & 0.73 \\
Sri Lanka & 9.49 & 0.54 & 0.58 & 0.48 & 0.64 \\
Sweden & 0.77 & 0.97 & 0.83 & 0.95 & 0.80 \\
Switzerland & 0.80 & 0.90 & 0.17 & 0.86 & 1.00 \\
Tanzania & 17.12 & 0.60 & 0.92 & 0.51 & 0.00 \\
Thailand & 5.11 & 0.82 & 0.50 & 0.67 & 0.93 \\
Tonga & 2.86 & 0.52 & 0.00 & 0.30 & 0.46 \\
Turkey & 81.60 & 0.70 & 0.42 & 0.24 & 0.00 \\
UK & 2.79 & 0.77 & 1.00 & 0.94 & 0.82 \\
Uruguay & 21.54 & 0.70 & 0.83 & 0.04 & 0.00 \\
US & 2.36 & 0.92 & 0.83 & 0.95 & 0.91 \\
Zambia & 35.17 & 0.66 & 0.17 & 0.57 & 0.00 \\
\hline
\end{tabular}


